\title{
THE FUTURE? LET'S FIRST WRITE A NARRATIVE OF OUR PRESENT
}

\author{
NASRIN STERLING \& JIANJUN XU \\ South China Sea Institute of Marine Metrology, Guangdong Ocean University, Zhanjiang, China
}

\begin{abstract}
Ecosystem degradation and unsustainable use of natural resources, coupled with climate change and other environmental stressors, are putting ecosystem services under threat. Also at risk is the health of citizens who live in damaged environments with polluted air, water and soil. The related dangers to health should give particular cause for concern, especially since most 21 st-century health care initiatives involve little spending on prevention and health protection. The rapid rise of China has created new challenges as political-economic drivers (urbanisation, industrialisation, mechanisation, globalisation and modernisation) multiply environmental stressors and caused mounting health problems. While there is a trade-off between ecosystem benefits and economic gain, it is essential to note that a healthy society is better able to deal with challenges as they emerge. There is a need for more investment in the monitoring of environmental stressors and climate change. This research paper addresses some of the health issues arising from environmental changes that prejudice the health and wellbeing of China's people. Along with China's anti-poverty measures, the situation requires multi-sectoral collaboration on multilevels within the health system. It needs to focus on disease prevention, underlying health problems, and contributing elements driven by social-political-economic factors. Such features of China's society and families as rapid population aging, the phenomenon of 'three generations - one roof' (elderly people, their children and grandchildren) as well as migration (rural-urban, urban-urban) need to be considered. The global challenge of the current COVID-19 pandemic is a wake-up call showing the need to pay more attention to the complexity of the system. There is a need to be conscious that the state of the ecosystem can change 'unexpectedly' and 'unannounced' in response to environmental change, causing 'undesirable' loss of ecological and economic resources and threatening the most basic need of the present generation, 'food and shelter' security.

Keywords: biodiversity, climate change, COVID-19 pandemic, ecosystem services, environmental health effect, food and shelter security, Sustainable Development Goals, system approach, three generations - one roof, trade-offs.
\end{abstract}

\section{INTRODUCTION}

In the last 50 years, populations have increased rapidly. The fast-growing need for humans for food and water has boosted consumption [1], [2], [3], [4]. Patterns of use and consumer choices have changed further with national and international marketing, media development, and the imposition of food safety requirements [5]. Because of modernisation, globalisation and highconsumption lifestyles, more lands have been cleared for agricultural expansion and reckless industrialisation and urbanisation [6]. Many natural resources are being overexploited, leaving degraded ecosystems both on land [7], [8] and in the oceans [9]. Food and shelter are fundamental to human needs and are largely provided by ecosystems and their services. However, the way we satisfy those needs differs between individuals and cultures [10].

An ecosystem consists of individuals and communities of plants and animals that act together as a whole and perform ecosystem functions that refer to the system properties, habitat and ecosystems processes [11]. The ecosystem services that directly or indirectly benefit humans include gas regulating and provisional and supporting services; air to breathe; water for drinking, for growing food and for providing hydroelectricity; food (from land, rivers, wetlands, lakes and the sea); and associated vital services such as nutrient cycling, 
pollination and biological control [9], [12]. However, recent human activities are affecting ecosystem services. Increased $\mathrm{CO}_{2}$ emissions from industries burning fossil fuels, as well as the impacts of nitrogen compounds from fertilisers, are among the causes leading to biodiversity loss, global warming and climate change [4]. As frequently reported by the IPCC (Intergovernmental Panel on Climate Change), Earth's average temperature has increased over the past century [13], [14], [15], [16]. Some significant impacts of climate change are rising sea levels, changes in deep-water circulation and the transmission of sound underwater, increased ocean temperatures, changes in dissolved oxygen and increases in ocean acidity. Climate change is a potential threat to ecosystems and their services, causing loss of biodiversity (including genetic and species diversity) as well as disruption of the dynamics within and between ecosystems and extinction at different spatial scales [9], [12]. Biodiversity is decreasing faster than at any time in the past [12].

Further, climate change is causing a range of related health risks such as infectious disease, extreme weather and food insecurity [17]. Apart from the displacement impacts of natural disasters, there are also physical impacts (e.g., heatwaves, diarrhoeal disease and detrimental effects on the safety and quality of consumed foods) and psychological effects (e.g., anxiety and depression) [18], [19], [20]. Warmer temperatures resulting from climate change have the potential to enable vectors to thrive [21], [22], [23], for example, by shortening the incubation period or breeding cycle of mosquitoes [21]. However, the '2018 WHO health and climate change survey report: tracking global progress' indicates that only $3 \%$ of Nationally Determined Contributions [online] in 2017-2018 (in relation both to climate change and to the Sustainable Development Goals [SDGs]) were linked to health-related goals (SDG3). When it comes to health risks related to climate change, the attention of most countries is directed to infectious diseases [24]. The report [24], in addition to the recent COVID-19 outbreak, indicates the need to address underlying health vulnerabilities. The World Health Organisation COVID-19 daily reports (from 21 January 2020 to the present) have repeatedly observed that older adults and people with underlying health problems make up the most vulnerable group [25]. By 13 May 2020, COVID-19 had caused some 287, 399 deaths around the world [26].

This paper will use the COVID-19 experience, the second Severe Acute Respiratory Syndrome (SARS) [27], to mention some of the relevant underlying health issues as well as the vulnerability of aged people. Relevant published papers are used to create a 'narrative' of the current period. The focus of the present paper is primarily on China in Asia, the world's largest continent with the largest concentrations of the human population. The region can be divided into five subregions: North Asia, South Asia, Central Asia, East Asia and West Asia. China is located in East Asia.

\section{UNDERLYING MEDICAL CONDITIONS}

According to the WHO, COVID-19 is caused by the virus SARS-CoV-2 [25]. It is believed to be a zoonotic infectious disease characterised by human-to-human transmission and with a fourteen-day incubation period [25], [27]. The outbreak of COVID-19 that appeared first in China late in 2019 became a public health emergency of international concern on 30 January 2020, before being officially categorised by the WHO as a pandemic on 11 March [28]. According to WHO reports, COVID-19 appears in a range of forms, including mild, acute and death in its severity. It has been reported that people suffering from underlying medical conditions such as respiratory disease, cancer, heart disease and diabetes are at higher risk [28]. 


\subsection{Communicable diseases}

Communicable diseases or infectious diseases are major public health issues in East and Southeast Asia [21] and are caused by bacteria, viruses, fungi and parasites, and can be spread directly or indirectly from one person to another. Environmental, socioeconomic and behavioural problems, as well as national and international travel, increase the spread of infectious diseases. The incidence of many infectious diseases such as diarrhoea, helminthiasis and tuberculosis increases where personal hygiene is poor, access to safe water and food is inadequate, and health services are lacking [21]. Some example of communicable diseases in the area includes tuberculosis (TB) and multi-drug-resistant TB (MDR-TB); sexually transmitted infections (STIs); dengue; and malaria [29], [30]. In China, rural-urban migration and urbanisation have accelerated the spread of these diseases during the 21 st century as socioeconomic changes have gone ahead [31], [32], [33], [34]. In addition to the spread of communicable diseases via human travel and migration, the accommodation provided to migrant workers in various countries is often crowded, with poor hygiene and sanitation, creating an ideal environment for disease transmission [21], [31], [33].

Moreover, zoonotic diseases result from infection with pathogens (bacteria, parasites, viruses, or unconventional agents as in the case of bovine spongiform encephalopathy) that have jumped from a non-human animal to a human [21]. Zoonotic factors are believed to have contributed to about $75 \%$ of some 30 new human pathogens over the past 30 years [21]. There are indications that COVID-19 has an ecological reservoir in bats, and it is possible that it made its way to humans through transmission first to another animal host (a wild animal, domestic food animal, or domesticated wild animal). Once in a human host, the disease is transmitted to other humans through droplets.

Flora and fauna have been altered as a result of human activities (e.g., rapid deforestation), creating an environment that favours pathogens [35]. Some factors contribute to the emergence and spread of zoonoses. According to Detels et al. [21], these factors include (i) intensive farming or animal husbandry practices that promote resistance in pathogens through the extensive use of antimicrobial agents and a lack of biosecurity measures; (ii) changing lifestyles and food habits; (iii) increased international travel and tourism; (iv) increased global trade; (v) illegal trading of wildlife; and (vi) climate change, deforestation and rapid industrialisation and urbanisation. While significant efforts are needed to secure food and other necessities, especially in emergencies, high levels of production and intensive practices may contribute to the further emergence and spread of infectious zoonoses (positive feedback loop).

\subsection{Non-communicable diseases}

Non-communicable diseases (NCDs) are not contagious and include diabetes mellitus, mental disorders, cancer, chronic respiratory and cardiovascular diseases, and musculoskeletal conditions. The incidence of NCDs is rising rapidly in developing countries such as China and India [36]. The underlying risk factors for NCDs are (i) social factors such as ageing, urbanisation, and globalisation; (ii) behavioural factors including tobacco use, alcohol consumption, unhealthy diet and inactive lifestyle; and (iii) physiological and metabolic factors such as increased blood pressure, raised lipids, increased blood glucose and obesity [36]. A recent study of public health risk factors relevant to NCDs shows that health systems are under the continual influence of external factors. For example, using corn syrup in food 
products contributes to excess calorie intake, raising the incidence of NCDs [37]. However, effective interventions such as dietary salt reduction [36] can limit the underlying risk factors for NCDs [38].

Obesity is directly linked with NCDs, particularly with diabetes, coronary heart disease, hypertension and dyslipidemia [39]. The population in the Asia region has undergone significant changes in areas such as lifestyle and nutrition, giving rise to non-communicable diseases. Until 1949, China experienced great famines with high mortality. Uneven economic development in different parts of the country led to unbalanced nutrition until a series of policies implemented by the government (e.g., significant land reallocation in rural areas and more advanced agricultural techniques) improved the food supply after 1949 and ended hunger [40]. Du et al. [40] study on China National Nutrition Survey (CNNS 1949-1992) suggests that intake of fat, carbohydrates and protein changed impressively between 1952 and 1982 (e.g., energy from edible oils and animal-source foods doubled). According to the authors, 'overweight emerged only after 1982' [40]. A healthy diet depends on (but is not limited to) the availability of food and adequate economic access to food throughout the country at different levels. Rising awareness of health and health-related issues, as well as of the health consequences of organisational practices and policy decisions, is bound to improve public health outcomes. The success of a health system should be measured in terms that include disease prevention and health protection. Nevertheless, health initiatives in the $21 \mathrm{st}$ century commonly spend no more than about $3 \%$ of their funds on prevention, with the bulk of their efforts going toward clinical problem management [37].

\section{AGED GENERATION}

According to the report of the Joint Mission that was conducted between 16 and 24 February 2020 regarding the ongoing outbreak of COVID-19 in China [41], the disease is usually mild in children, but mortality increases with age. It has been reported that in China, more than $20 \%$ of the deaths from COVID-19 have been among people more than 80 years old [41], [42]. The population in China is ageing relatively fast [43], primarily because of a decline of about $70 \%$ in fertility rates, from 5.6 children per woman in 1950 to 1.8 in 2000 [31]. A country with a relatively elderly population faces problems in a variety of areas, including public health and health insurance. According to a World Health Organisation assessment on China in $2015,80 \%$ of all deaths of people aged 60 or over in the country in 2012 were caused by chronic NCDs [43].

The health problems of the aged population have implications for the younger generations since, in Chinese culture, taking care of elders is the responsibility of younger people. This custom is known as 'three generations - one roof', describing the situation in which elderly people live with or are culturally bound up with family members, including their children and grandchildren. However, due to the earlier one-child policy [44], these older people have fewer children compared to the generation before them. The processes of socioeconomic transition are altering the traditional system of care for older people in China. As rural people from the younger generation migrate to the cities, for instance, responsibility for looking after elders falls on the remaining rural population/family members [34]. A WHO report predicts that the incidence of chronic NCDs in China will surge by 2030 by at least $40 \%$; accordingly, every young couple in the future will have to take care of four (or more) older family members who need care and assistance daily [43]. A further aspect of guarding health outcomes against environmental stressors relates to the need, while focusing on prevention, to strengthen multi-sectoral collaboration [36] between health and non-health sectors. The 
latter include finance, transportation, education, industrial development, environmental protection, civil society and public security along with healthy, affordable and sustainable food supply [43], [45], [46].

\section{SYSTEM COMPLEXITY}

The recent COVID-19 outbreak is an excellent example of the complexity of the health system and demonstrates that issues extend beyond infectious diseases themselves to structural and societal inadequacies. Economic, environmental, social, commercial and political factors have effects on health [47] and vice versa. The underlying health issues place heavy social and political-economic demands on the health system, including the provision of quality care services (notably, professional health workers, medical facilities and medicines), as well as imposing environmental demands such as the safe disposal of medical waste.

There is a need to examine the vulnerabilities, since 'no health system is perfect' [48]. These vulnerabilities and challenges extend to the global spread of infectious diseases, which compel the decision-makers and the global community to decide how to act [49]. Health crises such as contagious disease outbreaks require preparedness and effective responses to avoid catastrophe, as in the case of the Ebola epidemic in the Democratic Republic of the Congo, where the mortality rate is still over 60\% [50]. Apart from the financial impacts of the current pandemic, other social and economic effects such as the stigmatising of sufferers and discrimination against them, significant interference with international travel and transport, and potential transmission via global supply chain [28], [51].

Considering the complexity of the system, inside and outside of the health system, seeking swift solutions may be necessary for short term/emergency conditions. Still, it is less likely to be beneficial in the long term. Many environmental problems (such as pollution, depletion of soil and water resources), are either directly or indirectly relate to efforts to increase the rate of profit [52]. The rapid growth of the informal economic sectors in developing countries in Asia creates a highly competitive market that results in low-cost products for consumers [53]. The effect of increasing short-term output is to undermine the long-term resilience of the ecosystem, increasing its vulnerability to disturbance [54], [55]. Effective and sustainable use of natural resources, coupled with knowledge of the ecological systems involved, is essential if economic systems are to function profitably in the longer term [56]. All of which must attract China's policy maker's attention, considering the country's commitment under the SDGs to eradicate poverty by 2030 [57], and the shift in national objectives, since the 13th Five-Year Plan, from seeking high productivity to prioritising sustainability [9]. The Five-Year Plan sets forth China's strategic goals for economic and social development based on the recommendations of the Central Committee of the Communist Party of China (CPC). The 13th Five-Year Plan is the current plan with the defined strategies and main tasks, objectives and measures for China in 2016-2020.

\section{CONCLUSION}

This paper has briefly addressed some health-related issues resulting from human activities while highlighting certain aspects of the COVID-19 pandemic. The focus has been on the vulnerability of older people and others with a history of illness. In this effort, while it mentioned some of the challenges concerning age population, it also emphasised how obesity and zoonotic factors play an essential role in NCDs and the emergence of new human pathogens, respectively. While the focus of this paper is principally on China, many of the concepts apply to other countries too. 
China's health system needs to confront the country's underlying health issues and weaknesses along with its environmental problems and to take into account the potential role of the informal sector of the economy in the emergence of new human pathogens. Rapidly evolving microorganisms and endemic communicable diseases such as SARS demonstrate the vulnerability of the countries in the East and Southeast Asian region [21]. The outbreak of SARS in South China in 2003 [21] and of SARS-CoV-2(COVID-19) in Wuhan late in 2019 should be of particular concern. The corresponding interventions have required multi-sectoral collaboration on multiple levels and scales, including the global, national, regional and local. There is also a need for strategies of multi-purposing. For example, China has committed to targeted carbon emissions reduction (through participation in the COP21 climate change conference in Paris in 2015). If adopted on a sufficient scale, a healthy diet (as recommended by the Sustainable Healthy Diets Guiding Principles [58]) can provide opportunities for reducing GHG emissions from food systems while lowering the cost of health care services. Mitigating GHG emissions from the health care system is also possible through changes to health care delivery, such as reducing the quantities of drugs prescribed and thus lessening the use of drug manufacturing processes [59], [60], [61].

Trade-offs between economic gain and ecosystem conservation have always presented challenges for policymakers. Often, ecosystem services are not given adequate weight in policy decisions [11]. Securing public health outcomes against environmental stressors, however, poses more severe difficulties. The need to control COVID-19 has forced decisionmakers, perhaps reluctantly, to put the health of individual human beings and society first to minimise the social and economic impacts of the pandemic. It is important to remember that climate change impacts are not limited solely to physical or mental health but extend to many other areas, including food systems (production, trade, and exchange, availability, processing and packaging). With climate change intensifying the present environmental stressors, food production will become increasingly insecure [62], [63]. The assumption is often made that nature responds smoothly to gradual change. However, studies of coral reefs, oceans, lakes, forests and arid lands have shown that smooth transitions can be interrupted and that shifts to a contrasting state can occur unexpectedly and without warning, causing extensive damage to ecological and economic resources [64]. Triggering such events may be changed, such as land degradation [65], [66], nutrient loading and intensive fishing [64]. The response capacity of terrestrial organisms, populations, communities and ecosystems may not be sufficient to keep up with rapid climate change and allow adaptation to the new situation [67], [4]. Returning the system from a highly degraded state requires a great deal of effort and expensive intervention [64].

Biodiversity loss, growing GHG emissions and the degradation of ecosystems worldwide together show the need for overall choices in favour of ecosystems and the natural environment. Among the main stressors is climate change, some of whose worst effects will not be felt in full for generations. Grasping this concept is rendered much more challenging by the fact that some of the projected events may not happen in one's lifetime due to the ecological time scale, as well as lagging. There are gaps in the data, the data that exist are often insufficiently accurate and reliable, and temporal and spatial information may be inadequate. The situation requires careful management to avoid unpleasant surprises that fail to protect the coming generations. Efforts to conduct sustainable ecosystem management, as well as climate change mitigation and adaptation, will aid in improving public health and securing healthy environments. The practical outcome of these efforts will be to enhance productivity, healthy ecosystems, intergenerational health and prosperity and the long-term sustainability 
of natural resources. While the COVID-19 pandemic has highlighted some of the failures of the system (e.g., the acute shortage in various countries of testing kits and other indispensable equipment), it has nevertheless been possible to secure results using existing infrastructure, including virtual infrastructure for which global connections and services are available. Improvements in information and communications technology have allowed temporal and spatial boundaries to be crossed, and have provided opportunities for health benefits such as telemedicine or teleconsultation, globally and nationally. The question remains of whether, through some untoward development related to climate extremes or through presently unknown factors, those connections and services will be available in the future.

\section{REFERENCES}

[1] Erisman, J.W., Galloway, J., Seitzinger, S., Bleeker, A., Butterbach-Bahl, K., Reactive nitrogen in the environment and its effect on climate change. Current Opinion in Environmental Sustainability, 3(5), pp. 281-290, 2011.

[2] Klein et al., Adaptation opportunities, constraints, and limits. Constraints, 16, p. 4, 2014.

[3] Seitzinger et al., International geosphere-biosphere programme and earth system science: three decades of co-evolution. Anthropocene, 12, pp. 3-16, 2015.

[4] Primack, R.B., Sher, A., Introduction to Conservation Biology, Sinauer Associates, Incorporated, Publishers, 2016.

[5] Briones Alonso, E., Cockx, L., Swinnen, J., Culture and Food Security. Global Food Security, 2018.

[6] Newman et al., New Perspectives on Environmental Justice: Gender, Sexuality, and Activism, Rutgers University Press, 2004.

[7] Vlek, P.L., Nothing Begets Nothing. The Creeping Disaster of Land Degradation, 2005.

[8] Vlek, P.L., Khamzina, A., Tamene, L., Land degradation and the Sustainable Development Goals: Threats and Potential Remedies, 2017.

[9] FAO, The State of World Fisheries and Aquaculture 2018-Meeting the sustainable development goals, Food and Agriculture Organization of the United Nations Rome, 2018.

[10] Roberts et al., The Nature of Wellbeing: How Nature's Ecosystem Services Contribute to the Wellbeing of New Zealand and New Zealanders. Department of Conservation, 2015.

[11] Costanza, R., Arge, Groot R., Farberk, S., Grasso, M., Hannon, B., et al., The Value of the World's Ecosystem Services and Natural Capital. Nature, 387, pp. 253-260, 1997.

[12] IPBES, Summary for Policymakers of the Global Assessment Report on Biodiversity and Ecosystem Services of the Intergovernmental Science-Policy Platform on Biodiversity and Ecosystem Services, 2019

[13] Intergovernmental Panel on Climate Change. Summary for Policymakers, 2007.

[14] Ciais et al., Fifth Assessment Report of the Intergovernmental Panel on Climate Change, 2013.

[15] Intergovernmental Panel on Climate Change. Summary for Policymakers, 2014.

[16] Intergovernmental Panel on Climate Change. Global Warming of $1.5^{\circ} \mathrm{C}, 2018$.

[17] Ebi, K., Campbell-Lendrum, D., Wyns, A., The 1.5 Health Report: Synthesis on Health \& Climate Science in the IPCC Sr1. 5. World Health Organization, 2018.

[18] Holmes, A., Public Health Bulletin SA, 2011.

[19] Swim et al., Psychology and Global Climate Change: Addressing a Multi-Faceted Phenomenon and Set of Challenges, American Psychological Association: Washington, 2009. 
[20] Swim et al., Psychology's contributions to understanding and addressing global climate change. American Psychologist, 66(4), p. 241, 2011.

[21] Detels, R., Sullivan, S.G., Tan, C.C., Public Health in East and Southeast Asia: Challenges and Opportunities in the Twenty-first Century, 2012.

[22] World Health Organisation, Preventing Disease Through Healthy Environments, Geneva, 2016.

[23] Chen, C., Hsu, L., Environmental Issues in East and Southeast Asia. In Detels, 2012.

[24] World Health Organization. 2018 WHO Health and Climate Change Survey Report: Tracking Global Progress. Geneva, 2019.

[25] Coronavirus disease 2019, Situation reports, World Health Organisation Online, https:// www.who.int/docs/default-source/coronaviruse/situation-reports/20200423-sitrep94-covid-19.pdf?sfvrsn=b8304bf0_4

[26] Coronavirus disease 2019, Situation reports, World Health Organisation Online, https:// www.who.int/docs/default-source/coronaviruse/situation-reports/20200513-covid19-sitrep-114.pdf?sfvrsn=17ebbbe_4 (accessed 14 May 2020).

[27] Wallace, R., Liebman, A., Chaves, L. \& Wallace, R., COVID-19 and Circuits Of Capital. [online] Monthly Review, available at https://monthlyreview.org/2020/05/01/covid19-and-circuits-of-capital. 2020 (accessed 14 May 2020).

[28] Coronavirus disease 2019; Situation reports, World Health Organisation Online, https://www.who.int/docs/default-source/coronaviruse/situation-reports/20200311sitrep-51-covid-19.pdf?sfvrsn=1ba62e57_10 (accessed 24 April 2020).

[29] Commonwealth of Australia, Overview of Climate Change Impacts on Human Health in the Pacific Region, 2011.

[30] Jahncke, E.A., Paul, S., Rajan, R.S., Seow, A., Economic Globalization and Public Health in Asia. In Detels, 2012.

[31] Gong et al., Urbanisation and health in China. The Lancet, 379(9818), pp. 843-852, 2012.

[32] Mou, J., Griffiths, S.M., Fong, H.F., Dawes, M.G., Defining migration and its health impact in China. Public Health, 129(10), pp. 1326-1334, 2015.

[33] Mou, J., Griffiths, S.M., Fong, H., Dawes, M.G., Health of China's rural-urban migrants and their families: a review of literature from 2000 to 2012. British Medical Bulletin, 106(1), pp. 19-43, 2013.

[34] Liu, S., Griffiths, S., China faces equity challenges. Public Health, 125(10), pp. 669674, 2011.

[35] Bhatia, R., Narain, J.P., Plianbangchang, S., Emerging Infectious. In Detels, 2012.

[36] Low, W.-Y., Lee, Y.-K., Samy, A.L., Non-communicable diseases in the Asia-Pacific region: Prevalence, risk factors and community-based prevention. International Journal of Occupational Medicine and Environmental Health, pp. 1-7, 2015.

[37] Khamis, A-a., Overcoming the health system challenges in the 21 st century and beyond? Public Health, 168, pp. 47-49, 2019.

[38] World Health Organisation, available at http://www.euro.who.int (accessed 24 April 2020).

[39] Winichagoon, P., Tontisirin, K., Nutrition. In Detels, 2012.

[40] Du, S.F., Wang, H.J., Zhang, B., Zhai, F.Y., Popkin, B.M., China in the Period of Transition from Scarcity and Extensive Undernutrition to Emerging Nutrition-Related NonCommunicable Diseases, 1949-1992, 2014. 
[41] Coronavirus disease 2019, Situation reports, World Health Organisation Online, https:// www.who.int/docs/default-source/coronaviruse/who-china-joint-mission-on-covid19-final-report.pdf (accessed 24 April 2020).

[42] CNBC programme; online, https://www.cnbc.com/2020/03/09/who-says-threat-of-pandemic-has-become-very-real-even-as-china-recoveries-rise.html (accessed 24 April 2020).

[43] World Health Organisation, China country Assessment Report on Ageing and Health, 2015.

[44] Goldstein, B.Y., Parkin, D.M., Zhang, Z., Cancer. In Detels, 2012.

[45] Alderton et al., What is the meaning of urban liveability for a city in a low-to-middleincome country? 15(1), p. 51, 2019.

[46] Zhang, N., Trends in urban/rural inequalities in cardiovascular risk bio-markers among Chinese adolescents in two decades of urbanisation: 1991-2011. International Journal for Equity in Health, 17(1), p. 101, 2018.

[47] Hussain, S., Javadi, D., Andrey, J., Ghaffar, A., Labonté, R., Health Intersectoralism in the Sustainable Development Goal Era: From Theory to Practice. Globalisation and Health, 2020.

[48] Tedros Adhanom Ghebreyesus, World Health Statistics Overview 2019, p.p.v.

[49] Sethi, N., Research and Global Health Emergencies: On the Essential Role of Best Practice. Public Health Ethics, 11(3), pp. 237-250, 2018.

[50] Huster, K., Healy, J., Congo's Ebola Epidemic: A Failed Response and the Need for a Reset. 2019.

[51] Coronavirus disease 2019; Situation reports, World Health Organisation Online, https:// www.who.int/publications-detail/rational-use-of-personal-protective-equipment-forcoronavirus-disease-(covid-19)-and-considerations-during-severe-shortages (accessed 24 April 2020).

[52] Gutenschwager, G., Natural causes: Essays in ecological Marxism. Regional Studies, 34(1), p. 94, 2000.

[53] Amin, A., Singh, A., The Informal Sector in Asia from the Decent Work Perspective, International Labour Organization, 2002.

[54] Walker, B., Salt, D., Resilience Thinking: Sustaining Ecosystems and People in a Changing World, Island press, 2012.

[55] Plummer, K., Ritzer, G., The Wiley-Blackwell Companion to Sociology, Wiley-Blackwell Chichester, 2012.

[56] Braat, L.C., de Groot, R., The ecosystem services agenda: bridging the worlds of natural science and economics, conservation and development, and public and private policy. Ecosystem Services, 1(1), pp. 4-15, 2012.

[57] UNDP. 2020. 2019 / UNDP In China; online, https://www.cn.undp.org/content/china/ en/home/presscenter/articles/2019.html (accessed 24 April 2020).

[58] Organisation, W.H., Sustainable Healthy Diets: Guiding Principles, Food \& Agriculture Org., 2019.

[59] Sattler, B., The greening of health care: environmental policy and advocacy in the health care industry. Policy, Politics, \& Nursing Practice, 4(1), pp. 6-13, 2003.

[60] Chung, J.W., Meltzer, D.O., Estimate of the carbon footprint of the US health care sector. JAMA, 302(18), pp. 1970-1972.

[61] Lynch, T., Greening health care: how hard can that be? Journal of Health Services Research \& Policy, 16(4), pp. 247-248, 2011. 
[62] Onuh, M., Ohazurike, N., Climate Change: A Threat to Agricultural Production in Nigeria. Journal of Agriculture and Food Sciences, 9(1), pp. 14-21, 2011.

[63] Ingram, J., Ericksen, P., Liverman, D., Food Security and Global Environmental Change, Routledge, 2012.

[64] Scheffer, M., Carpenter, S., Foley, J.A., Folke, C., Walker, B., Catastrophic shifts in ecosystems. Nature, 413(6856), p. 591, 2001.

[65] Hobbs, R.J., Hopkins, A, editors. From Frontier to Fragments: European Impact on Australia's Vegetation. Proceedings of the Ecological Society of Australia, 1990.

[66] Saunders, D., Hobbs, R.J., Habitat Reconstruction: The Revegetation Imperative. Conserving Biodiversity: Threats and Solutions.,1995

[67] Penuelas, J., Sardans, J., Estiarte, M., Ogaya, R., Carnicer, J., Coll, M., et al. Evidence of current impact of climate change on life: a walk from genes to the biosphere. Global Change Biology, 19(8), pp. 2303-2038, 2013. Penuelas et al., 2013 